\title{
Investigation of reinforced concrete columns with recessed longitudinal rods without transverse reinforcement
}

\author{
Viktor Muradyan ${ }^{1, *}$, Dmitry Mailyan ${ }^{1}$, Aksel Mkrtchyan ${ }^{2}$, Sergey Osadchenko ${ }^{1}$ \\ ${ }^{1}$ Academy of Civil Engineering and Architecture Don State Technical University, 344022, \\ Sotsialisticheskaya, 162, Rostov-on-Don, Russian Federation \\ ${ }^{2}$ Scientific Research Center "Design and Expertise", 0022, Avan, First micro, 1/7-5, Yerevan, \\ Armenia
}

\begin{abstract}
The article deals with the feasibility of a significant increase in the thickness of the protective layer of longitudinal rods in compressed reinforced concrete columns. We describe the experimental data of the work of the reinforced concrete columns with recessed longitudinal reinforcement without transverse reinforcement. We provide a method for calculation of such structures and optimum parameters of the thickness of the protective layer on the criterion of maximum critical efforts.
\end{abstract}

\section{Introduction}

When positioned in the compressed reinforced concrete structures near the edges of the longitudinal rods in compliance with the minimum protective layer, the setting of transverse reinforcement is required to prevent buckling of the longitudinal rods [1-15]. It seems appropriate to ensure sufficient stability of the longitudinal rods due to a significant increase in the thickness of the protective layer. This would eliminate the transverse reinforcement (fully or partially), thus, resulting in substantial savings of reinforcing steel, having a function of several factors: the thickness of the protective layer, the flexibility of the reinforcing rod, the concrete strength (since an increase in concrete strength results in adherence to the reinforcement), the type of reinforcement etc.

The analysis of the published results of experimental research work on the compressed concrete elements made by various scientists of our country and abroad, shows that in some cases the amount of transverse reinforcement in such structures can be reduced by increasing the maximum allowable distance between the clamps.

For example, in the work [13] a special experiment was carried out on the compressed reinforced concrete columns with a constant percentage of longitudinal reinforcement and with varying the diameter and the step of the clamps in a certain class of heavy concrete. The distance between the clamps was expected to increase three times, compared with the maximum allowable norms.

* Corresponding author: muradyan2007@yandex.ru 
The work [12] investigated the strength and the crack resistance of piles without transverse reinforcement with centrally and peripherally located longitudinal wire reinforcement or bending and eccentric compression.

Refusing to use the transverse reinforcement allowed to reduce the metal consumption and the manufacturing cost of piles drastically. However, the range of application of such structures is more limited than for piles with transverse reinforcement.

\section{Literature review}

Investigation of reinforced concrete columns with recessed longitudinal rods without transverse reinforcement is a very actually problem of modern building and constructions. A lot of scientists devote their scientific works to this problem. We can see the parts of this theme in the works of V.P. Agapov, A.V. Vasiliev; A.L. Balushkin; A.D. Beglov, R.S. Sanzharovsky; A.V. Benin; A.M. Blyagoz, O.V. Shilyaeva, R.A. Khunagov; S.F. Klovanich, D.I. Bezushko; E.A. Korol, Y.A. Kharkin; V.A. Muradyan, D.R. Mailyan; V.A. Muradyan, D.R. Mailyan; V.A. Muradyan, D.R. Mailyan; V.A. Muradyan, O.V. Shilyaeva, A.M. Blyagoz; A.D. Nazarov; a report on the research work; SP 52-101-2003; SP 52-1022004 at their articles : Simulation of rectangular columns with volume elements using superelement technology [1]; Features of cracking concrete construction process modeling stage, close to the destruction [2]; The theory of reinforced concrete structures calculation for strength and stability [3]; Finite element method for estimating the degree of corrosion of reinforcement on the analysis of defects on the surface of the concrete element [4]; Simulation of the stability of the concrete panels [5]; The finite element method in nonlinear analysis of spatial reinforced concrete structures [6]; Investigation of tenselydeformed state of the three-layer reinforced concrete elements and the structure of monolithic section by computer simulation [7]; Reinforced concrete stands with recessed longitudinal rods without transverse reinforcement [8]; Method of calculation of eccentrically compressed reinforced concrete columns [9]; Stability of reinforcement rods in compressed reinforced concrete column [10]; On the calculation of reinforced concrete columns with the finite element method [11]; Investigation of strength and crack resistance of pre-tense piles without transverse reinforcement [12]; Experimental testing of the limiting distance between the clamps in the compressed concrete elements [13]; Concrete and reinforced concrete constructions without reinforcement tense [14]; Pre-tense concrete structures [15].

\section{Experimental section}

In the regulations there are no direct instructions in the calculation of piles with increased thickness of the protective concrete layer [14-15]. The calculation of compressed loweccentricity central reinforced piles is the most difficult.

In order to obtain experimental data on the load-bearing capacity, the crack resistance and the deformability of reinforced concrete columns without transverse reinforcement the following experiments were carried out. There was an investigation of the influence of the following factors such as: the thickness of the concrete cover, the reinforcement ratio, the initial eccentricity of the external compressive force on the resistance of these structures to compression.

The research program included the production and testing of 24 prototypes (Fig. 1). In accordance with the program the main factors, affecting the operation of the elements under load, varied within the following limits:

- thickness of the concrete cover $-\alpha=3 \mathrm{~cm}, 5 \mathrm{~cm}$ and $7 \mathrm{~cm}$; 


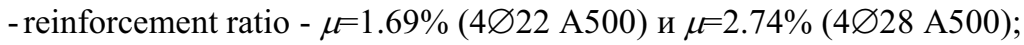

- the relative eccentricity of external force $-e_{o} / \mathrm{h}=0$ - central compression, $e_{o} / \mathrm{h}=$ 0.15 - eccentric contraction with the application of the compressive force at the border section of the core element.

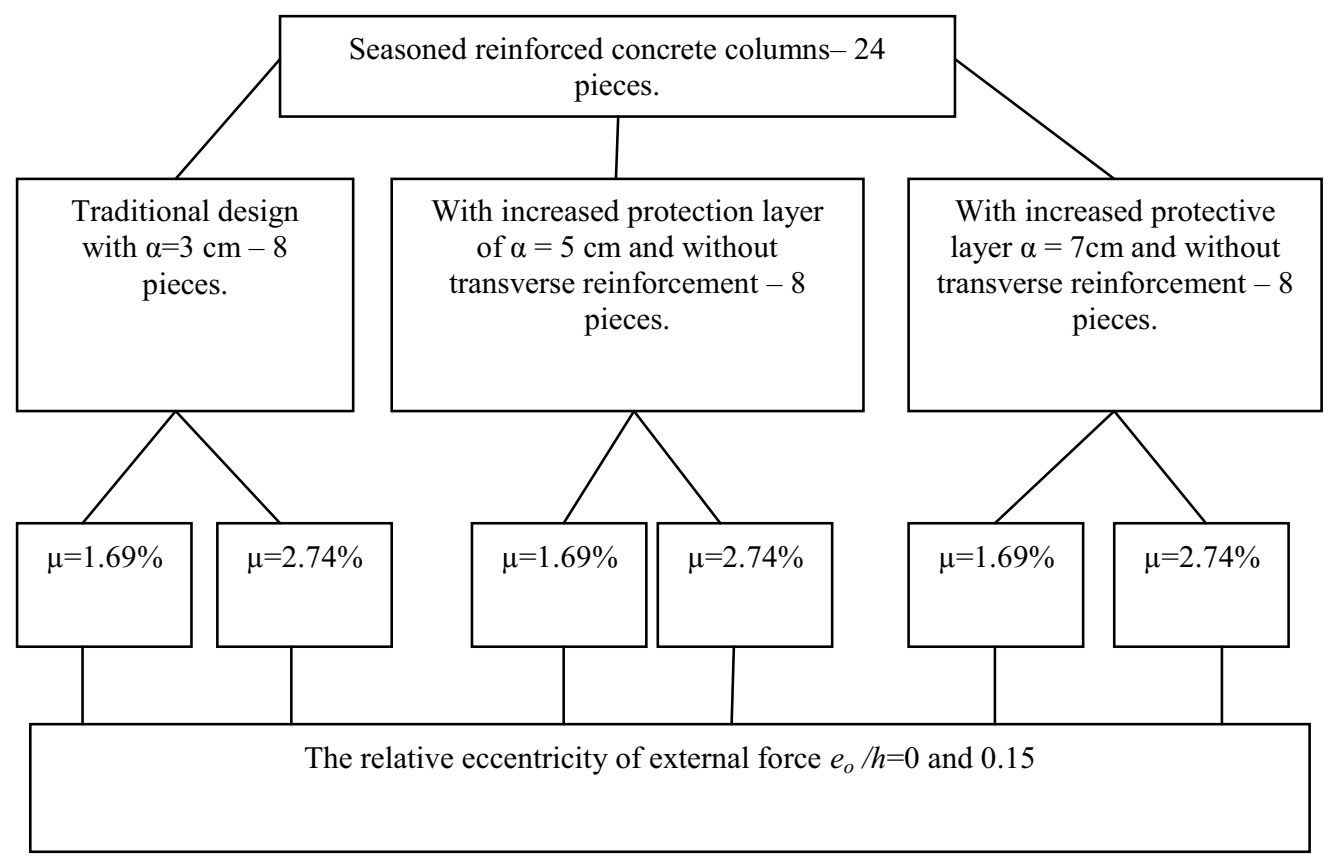

Fig.1. Seasoned reinforced concrete columns test program.

"Numerical experiment" was carried out in order to obtain additional data on the work of compression prestressed concrete elements of increased flexibility.

In the program "numerical experiment" there was a wide variety of the following factors: the thickness of the reinforced concrete cover, the reinforcement percentage, the initial eccentricity of the application of an external compressive force.

Prototypes manufactured in accordance with the program of experimental studies, represented a square tower with height and width of $300 \mathrm{~mm}$. Element length $-1800 \mathrm{~mm}$.

There are two types of samples reinforcement - $4 \varnothing 22$ A500 $(\mu=1.69 \%)$ and $\varnothing 28$ A500 $(\mu=2.74 \%)$. The whole longitudinal reinforcement in the elements of the traditional design was located near the edges of elements with a protective layer of $3 \mathrm{~cm}$ (Fig. 2). In the elements with an increased protective concrete layer, the transverse reinforcement was carried out in the form of grid reinforcement $\varnothing 6$ Bp500 only at the ends of the element. In the elements with a traditional reinforcement, the transverse reinforcement was realized in the form of closed clamps over the whole length of the column. Grids and clamps for transverse reinforcement were produced by using the contact welding. 

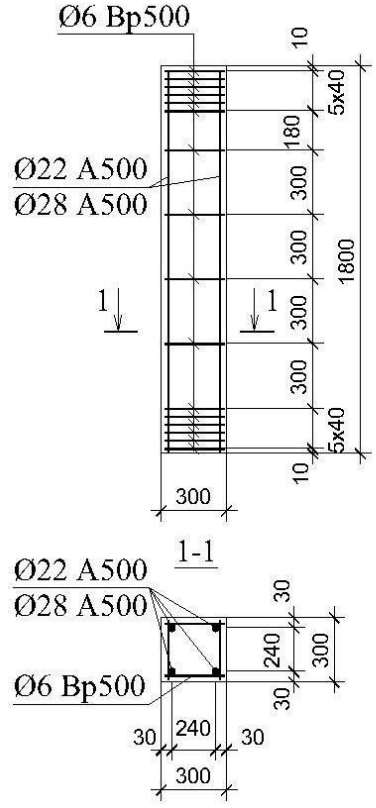
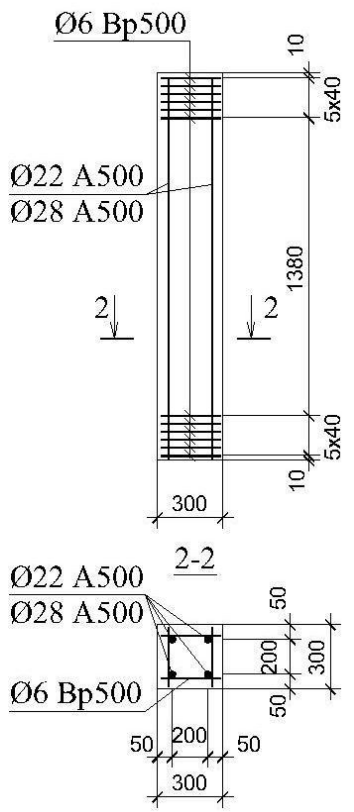
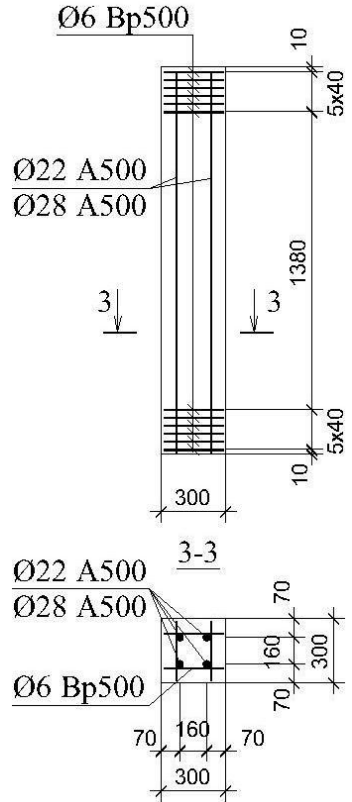

Fig.2. Structures of seasoned reinforced concrete columns.

\section{Results section}

Experiments have shown that the load bearing capacity of reinforced concrete stands with an increase in the protective layer of $5 \mathrm{~cm}$ and without transverse reinforcement of columns under central compression was reduced to $16.2 \%$ (with armature $4 \varnothing 22 \mathrm{~A} 500$ ) and $15 \%$ (for fixture $4 \varnothing 28 \mathrm{~A} 500)$. By increasing the thickness of the protective layer to $7 \mathrm{~cm}$, stands without transverse reinforcement have shown almost the same results as conventional reinforcement with traditional transverse reinforcement.

Reinforced concrete stands, experienced with eccentricity $e_{o} / \mathrm{h}=0.15$, have shown similar results. So, for stands with $\mu=1.69 \%$ there was a decrease in the absence of the bearing capacity of transverse reinforcement and the thickness of the protective layer of 5 $\mathrm{cm}$ at $11 \%$, while for $\mu=2.74 \%$ decrease was only $\mathrm{Nu}-7 \%$. The increase in thickness of the protective layer up to $7 \mathrm{~cm}$ resulted in an almost complete coincidence of bearing capacity of such columns without transverse reinforcement and traditional to it (see Table. 1).

Table 1. Main results of the testing of experimental reinforced concrete columns.

\begin{tabular}{|c|c|c|c|c|c|c|}
\hline $\begin{array}{c}\text { Samples } \\
\text { code }\end{array}$ & $N_{u}, \mathbf{K N}$ & $\frac{N_{u}}{N_{u(T)}}$ & $\varepsilon_{b u} \mathbf{x} \mathbf{1 0}^{\mathbf{5}}$ & $\varepsilon_{b a u} \mathbf{x} \mathbf{1 0}^{\mathbf{5}}$ & $\frac{\varepsilon_{b \alpha u}}{\varepsilon_{b u}}$ & $\boldsymbol{R}_{b}, \mathbf{M P a}$ \\
\hline $\mathrm{K} 3-22-0$ & 3700 & 1 & 241 & 38 & 0.158 & 32.8 \\
\hline $\mathrm{K} 5-22-0$ & 3100 & 0.838 & 153 & 89 & 0.582 & 31.6 \\
\hline $\mathrm{K} 7-22-0$ & 3680 & 0.995 & 232 & 56 & 0.241 & 33.4 \\
\hline $\mathrm{K} 3-22-0,15$ & 2780 & 1 & 272 & - & - & 34.1 \\
\hline
\end{tabular}




\begin{tabular}{|c|c|c|c|c|c|c|}
\hline K5-22-0,15 & 2500 & 0.899 & 189 & - & - & 32.2 \\
\hline K7-22-0,15 & 2800 & 1.007 & 267 & - & - & 31.9 \\
\hline K3-28-0 & 4120 & 1 & 260 & 34 & 0.131 & 33.4 \\
\hline K5-28-0 & 3500 & 0.850 & 180 & 69 & 0.383 & 30.9 \\
\hline K7-28-0 & 4180 & 1.015 & 255 & 47 & 0.184 & 33.2 \\
\hline K3-28-0,15 & 2900 & 1 & 284 & - & - & 32.2 \\
\hline K5-28-0,15 & 2700 & 0.931 & 209 & - & - & 31.8 \\
\hline K7-28-0,15 & 2900 & 1 & 284 & - & - & 33.1 \\
\hline
\end{tabular}

Therefore, the carried out experiments showed that ensuring the stability of the longitudinal rods while maintaining the carrying capacity of compressed concrete elements can be achieved without transverse reinforcement by increasing the thickness of the protective concrete layer.

According to the results of our testing of reinforced concrete stands with A500 grade reinforcement, the experienced diagrams on the central compression were identified $" \sigma_{b}$ $\varepsilon_{\mathrm{b}}$ ". To do this, at each stage, the load stress in the concrete was determined by the formula:

$$
\sigma_{b i}=\frac{N_{i}-N_{s i}}{A_{b}},
$$

where $N_{s i}=A_{s} \cdot E_{s} \cdot \varepsilon_{s i}$ - perceived reinforcement effort ;

$\mathrm{N}_{\mathrm{i}}$ - current value of the longitudinal force,

$A_{b}$ - concrete sectional area (net area of reinforcement).

The analysis of the experimental diagram $" \sigma_{b}-\varepsilon_{b}$ " has shown that in contrast to the concrete deformation diagram of unreinforced prisms, the coordinate of the vertex in the presence of reinforcement A500 is shifted to the right and upward. Noted above indicates that the presence of reinforcement increases strength and deformation, corresponding to limiting stresses.

This empirically diagram $" \sigma_{\mathrm{b}}-\varepsilon_{\mathrm{b}}$ " gives a good description of the SEB-FIP dependence, which in this case takes the following form:

$$
\frac{\sigma_{b}}{R_{b}}=\frac{k_{b} \eta_{b}-\eta_{b}^{2}}{1+\left(k_{b}-2\right) \eta_{b}},
$$

where $\eta_{b}=\varepsilon_{b} / \varepsilon_{b R}^{*} ; \quad k_{b}=E \cdot \varepsilon_{b R}^{*} / R_{b}^{*}$.

Coordinates of the top of the diagram " $\sigma_{b}-\varepsilon_{b}$ " may be determined by the formulas:

$$
\begin{aligned}
& R_{b}^{*}=R_{b}(1+0.15 \mu) ; \\
& \varepsilon_{b}^{*}=\varepsilon_{b R}(1+0.075 \mu) .
\end{aligned}
$$

Calculation of eccentrically compressed elements can be produced by the static equations having elements rectangular cross-section as follows: 


$$
\begin{gathered}
N_{u} \cdot e=\alpha_{b} R_{b}^{*} b x\left(h_{0}-0.5 x\right)+R_{s c} A_{s}^{\prime}\left(h_{0}-a^{\prime}\right) ; \\
\alpha_{b} R_{b}^{*} b x+R_{s c} A_{s}^{\prime}-\sigma_{s} A_{s}-N=0 .
\end{gathered}
$$

\section{Discussion section}

Calculation of seasoned concrete stands free of tension reinforcement on the A500 of the developed proposals showed significantly better convergence of experimental and theoretical data than the calculation according to the regulations. The sum of squared deviations, taking into account the actual stress in the reinforcement and concrete, reduces as compared with the calculation according to SNIP in 5.4 times, as compared with the calculation taking into account only the actual stress in the reinforcement in 2 times.

It should be noted that an increase in force sensed by reinforcement element in the compressed area, on the one hand, is more intense stress redistribution from the concrete to the reinforcement, which leads to an increase in compressive stress limit in the reinforcement, and on the other hand - the implementation of the descending portion " $\sigma_{b}-\varepsilon_{b} "$ diagram leads to lower stresses in the concrete. Apparently, the bearing capacity of concrete stand with increasing percentage of reinforcement steel free of tension will always increase because increasing efforts sensed reinforcement is greater than the fall in force sensed by the concrete. However, when exceeding a certain percentage of reinforcement optimum value the efficiency of high-strength reinforcement may be reduced.

\section{Conclusions}

According to the results we have come to the following conclusions: we have got experimental data on the work load of reinforced concrete columns with recessed fixture without transverse reinforcement by varying the thickness of the protective layer, the percentage of longitudinal reinforcement, the relative eccentricity of the external force. We have found that the destruction of such elements is more brittle as compared with traditional designs with reinforcement.

It was proved that by increasing the thickness of the protective layer to $7 \mathrm{~cm}$, the columns without any transverse reinforcement have essentially the same load carrying capacity as traditional reinforcement elements. Reducing the thickness of the protective layer of $5 \mathrm{~cm}$ has led to premature failure of the columns because of the buckling of longitudinal reinforcement. The increasing of the percentage of longitudinal reinforcement raises the bearing capacity. The lower the eccentricity of the external force, the more the bearing capacity.

\section{References}

1. V.P. Agapov, A.V. Vasiliev, Structural Mechanics of engineering structures and buildings. 4, 48-54 (2012)

2. A.L. Balushkin, Bulletin of Civil Engineers. 3, 49-54 (2010)

3. A.D. Beglov, R.S. Sanzharovsky, The theory of reinforced concrete structures calculation for strength and stability. Modern standards and European standards. 211 (2008)

4. A.V. Benin, Finite element method 1, 112-114 (2008) 
5. A.M. Blyagoz, O.V. Shilyaeva, R.A. Khunagov, New technologies 3, 114-119 (2012)

6. S.F. Klovanich, D.I. Bezushko, The finite element method in nonlinear analysis of spatial reinforced concrete structures (Publisher ONMU, (2009)

7. E.A. Korol, Y.A. Kharkin, Herald MSUCE. 4, 117-120 (2010)

8. V.A. Muradyan, D.R. Mailyan, Calculation and design of reinforced concrete structures: a collection of scientific works, 94-95 (2009)

9. V.A. Muradyan, D.R. Mailyan, Engineering Vestnik of Don. 4 (2012)

10. V.A. Muradyan, D.R. Mailyan, Stability of reinforcement rods in compressed reinforced concrete column. Construction - 2010: Proceedings of the conf. (2010)

11. V.A. Muradyan, O.V. Shilyaeva, A.M. Blyagoz, New Technologies. 3 (2013)

12. A.D. Nazarov, PhD Thesis (2004)

13. Experimental testing of the limiting distance between the clamps in the compressed concrete elements: a report on the research work (2007)

14. Russian Standard SP 52-101-2003

15. Russian Standard SP 52-102-2004 